\title{
The Effect of Cognitive and Affective trust on Sport Fan Behavior after Team's Loss: A case of the US men's national soccer team viewership
}

\author{
Namkyeong Jang ${ }^{1}$, Jisuk Chang ${ }^{1 *}$ and Yukyoum Kim ${ }^{2}$ \\ ${ }^{1,2}$ Department of Physical Education, Seoul National University, Seoul, Korea
}

\begin{abstract}
[Purpose] The purpose of this study was to examine the role of trust on sport fan behavior following the favored team's loss. [Methods] Online survey modes were employed to collect the data. A total of 300 individuals participated in the study, of which 288 were valid and therefore analyzed. To test the hypotheses, structural equation modeling was conducted using Mplus 8. [Results] The findings are as follows. First, cognitive trust had a significant effect $(+)$ on future viewing intention. Second, affective trust had a significant effect( $(+)$ on future viewing intention. Third, cognitive trust had a significant effect(-) on switching behavior. Fourth, affective trust had no significant effect on switching behavior. Fifth, team identification moderated the relationship between affective trust and switching behavior. [Conclusions] The results of this study suggest that sport fans' trust affects fan behavior following a team's loss. Therefore, professional sport teams should seek to establish strong affective trust and cognitive trust.
\end{abstract}

Key words: Cognitive trust, Affective trust, Reviewing intention, Switching intention, Team identification

\section{서 론}

\section{연구필요성 및 목적}

스포츠팬은 자신이 응원하는 팀이 승리하기를 기대한다. 팀의 승리는 스포츠팬을 만족시키고 소비자가 스포츠 이벤 트를 긍정적으로 생각하게 한다(Biscaia, Correia, Rosado, Maroco, \& Ross, 2012). 경기의 승패는 스포츠 팬 정서에 강한 영향을 미친다(Madrigal, 2003). 그렇지만, 스포츠에서 패배는 필연적이기 때문에 언제나 기분 좋은 경 험만 할 수는 없다. 승자가 승리의 달콤함을 만끽할 때, 다른 한 쪽은 패배의 씁쓸함을 느낄 수밖에 없는 것이다. 일반상 품 소비자와는 다르게 자신이 응원하는 팀의 실패는 스포츠 소비자 정체성과 밀접한 관계를 갖는다(Wann \&

논문 투고일 : 2021.04.19.

논문 수정일 : 2021.06.10.

게재 확정일 : 2021.06.28.

* 교신저자 : 장지석(giberish@snu.ac.kr)
Branscombe, 1993). 자신은 게임 결과에 대해 어떤 영향 을 미칠 수도 없지만, 팀의 패배를 마치 자신이 패배한 것처 럼 느끼는 것이다(Hirt, Zillmann, Erickson, \& Kennedy, 1992; Partridge \& Wann, 2020).

특히, 응원하는 팀의 패배는 팬이 경기에 대해 불만족하 는 결정적 원인이다. 팬은 팀 패배로 인해 분노, 고통, 수치심 과 같은 다양한 감정을 느낀다(Jones, Lane, Bray, Uphill, \& Catlin, 2005; Madrigal, 2008). 그럼에도 불구하고, 스 포츠팬들은 지속적으로 자신이 좋아하는 팀을 바꾸지 않는 모습을 보인다. 이는 스포츠 팬이 응원하는 팀의 패배로 인 해 경험하는 인지와 부정적 감정을 극복하는 능력이나 방법 이 있다는 것을 의미한다.

스포츠 경영학 연구자들은 이러한 현상을 연구하기 위해 많은 노력을 쏟아왔다. 특히, 스포츠팬이 응원하는 팀의 패 배로부터 받는 스트레스에 어떻게 대처(Coping) 해야 하는 지에 대한 연구가 활발하게 이루어졌다. 패배한 팀과 자신을 분리하거나(Snyder, Higgins, \& Stucky 1983), 승리한 팀 
을 비난하고(Cialdini \& Richardson, 1980), 내집단 구성 원에 대한 편향적 사고(Doosje, Branscombe, Spears, \& Manstead, 1998)에 대한 연구가 진행되었다. 위 연구들은 응원하는 팀의 패배로 인한 소비자 반응을 연구했다는 점에 서 그 의의가 있다. 하지만, 응원하는 팀의 패배가 스포츠 팬 의 향후 소비의도에 어떠한 영향을 미치는 지에 대한 연구는 상대적으로 부족한 상황이다. 특히, 패배로 인한 부정적 행 동을 지연시키는 변수로써 신뢰에 대한 탐구는 부족했다. 신 뢰는 불안정한 상황에서 특정 대상과 관계 유지에 중요한 역 할을 하며(Portes, 1998), 성공적인 관계 유지를 위해 필수 적이다(Dwyer, Schurr, \& Oh, 1987; Garbarino \& Johnson, 1999). 스포츠 관람객의 신뢰에 관련된 연구를 살 펴보면, $\operatorname{Kim}$ (2005)은 스포츠 이벤트 경기 참여자를 대상으 로 한 연구에서 경기에 대한 관람만족이 이벤트에 대한 신뢰 에 영향을 미치는 것을 확인하였다. $\mathrm{Kim}, \mathrm{Kim}, \& \mathrm{Kim}$ (2012)은 프로축구 관중의 관람만족이 팀 신뢰에 영향을 미 친다고 주장하였다. Park \& Hong (2020)의 스포츠 인플루 언서 이용동기에 관한 연구에서는 소비자의 인플루언서가 제공하는 정보 공유, 관계 유지, 즐거움은 신뢰에 긍정적 영 향을 미쳤다. 또한, 인플루언서에 대한 신뢰는 제품 구매의 도에 긍정적 영향을 미쳤다. $\mathrm{Ha} \& \mathrm{Kim}$ (2021)은 여자 프로 농구 관중을 대상으로 한 연구에서 자아일치성이 팀 신뢰에 미치는 영향을 확인하였다. 팀 신뢰는 팀 감정과 팀 몰입을 통해 재관람의도에 영향을 미쳤다. 참여 스포츠 소비자의 신 뢰 연구를 살펴보면, Seok, Cho, \& Ko (2017)의 대학피트 니스 센터 이용자에 대한 연구에서 서비스 품질은 소비자 신 뢰에 영향을 미치며, 소비자 신뢰는 이용지속의도에 영향을 미치는 것을 확인하였다. $\operatorname{Lim} \& \operatorname{Kim}$ (2019)의 연구에서 해 양스포츠 참여자의 관여도(Playfulness, Importance, Interest)는 신뢰에 영향을 미치는 것으로 나타났다. Jeong (2020)은 온라인 스포츠용품 구매자의 기술수용요인이 소 비자 신뢰에 영향을 미치며, 신뢰는 소비 행동과 만족도에 긍정적 영향을 미치는 것을 확인하였다. 스포츠 용품산업 분 야의 신뢰 연구 역시 다른 분야와 유사한 연구 결과를 보인 다. Hong (2012)의 온라인 스포츠 상품 구매의사모형에 따 르면 지각된 편의성은 신뢰에 긍정적 영향을 미친다. 또한, 신뢰는 지각된 유용성과 구매의사에 긍정적 영향을 미치는 것으로 나타났다. Lee \& Hong (2016)의 소셜커머스를 통 한 스포츠 용품 구매 연구에서는 소셜커머스 구매속성과, 만 족이 신뢰에 영향을 미쳤다. 신뢰는 재구매의도에 영향을 미
쳤다. Lee \& Joo (2020)의 아웃도어 브랜드에 관한 연구에 서 브랜드 태도는 브랜드 신뢰에 영향을 미치며, 신뢰는 긍 정적 미래행동 의도에 영향을 미쳤다.

스포츠 경영학 분야에서 진행된 다양한 신뢰에 관한 연구 는 신뢰가 소비자 행동에 어떤 영향을 미치는지, 그리고 신 뢰 향상을 위해서 어떻게 해야 하는지에 대한 귀중한 지식을 제공한다. 그러나, 신뢰를 단일 요인으로 측정했다는 한계가 있다(Ha \& Kim, 2021; Hong, 2012; Kim, 2005; Kim \& Trail, 2011; Lee \& Hong, 2012; Lim \& Kim 2015). 신뢰 를 다차원적 개념으로 보는 연구(McAllister, 1995; Lewicki \& Bunker, 1995; Lewicki \& Tomlison, 2003) 들이 진행됨에 따라, 신뢰를 구분하는 특성이 각기 다른 역 할을 하는 것으로 예상된다. 소비자 행동 분야의 선행 연구 들에 의하면 인지적 신뢰와 정서적 신뢰는 각기 다른 선행요 인에 의해 영향을 받으며 특히 충성도(loyalty)와 관련된 행 동에 각기 다른 영향을 미치는 것으로 나타났다(Chai, Malhotra, \& Alpert, 2015; Ha, John, John, \& Chung, 2016). 또한, 인지적신뢰와 정서적신뢰가 미치는 영향이 상 황에 따라 달라질 수 있다는 것을 암시하고 있다. Chai, Malhotra, \& Alpert (2015)의 연구에서 은행 직원에 대한 인지적신뢰가 정서적신뢰보다 은행의 지속 이용 의도에 더 욱 큰 영향을 미치는 것으로 나타났다. 반면, 정서적신뢰는 소비자가 기업의 서비스 실패를 용서하는 데에 더욱 크게 작 용한다(Ozdemir, Zhang,Gupta, \& Bebek, 2020). 스포 츠 소비는 경험적 소비이기도 하지만 인지적인 평가가 끊임 없이 이뤄지는 소비이기도 하다. 모든 스포츠 종목은 경기 시작 전, 중간, 그리고 종료 후에도 승패 확률 및 원인을 끊임 없이 분석하는 과정이 동반된다. 또한, 스포츠 팬들은 자신 이 응원하는 팀과 강한 감정적 유대감을 공유하는 것으로 알 려져 있으며 팀의 행보를 자신의 일처럼 걱정하고 고심하기 도 한다. 따라서, 스포츠 소비자가 가진 팀에 대한 신뢰의 세 부개념에 따라 소비자의 행동이 어떻게 달라질 수 있는지 확 인하는 연구가 필요하다. 특히, 기존 스포츠 소비자 행동 분 야에서 상대적으로 연구가 부족했던 신뢰를 세부적으로 분 류하고 이에 기반한 스포츠 소비자 행동의도를 파악하는 것 은 의미가 있을 것이다.

또한, 대부분 선행연구는 신뢰에 영향을 미치는 선행요인 과 신뢰의 관계를 주로 설명해왔다(Garbarino \& Johnson, 1999; Pavlou \& Chellappa, 2001; Hong, 2012; Kim, 2005). 예를 들어, 서비스 실패나 불만족이 소비자의 신뢰에 
부정적 영향을 미친다는 것이다(Yu, Lee, \& Han, 2016). 반 면 소비자가 기존에 가지고 있던 신뢰가 서비스 실패나 패배 에 대한 소비자의 반응에 미치는 영향에 대한 연구는 상대적 으로 부족했다. 따라서 기존에 구축해 놓은 신뢰가 패배 이후 소비자의 부정적 행동을 지연시키거나, 긍정적 행동을 증폭 시키는데 어떤 역할을 하는지 검증하는 연구는 의미가 있을 것이다. 또한 인지적신뢰와 정서적신뢰가 가진 특성에 따라 소비자가 다른 행동을 보이는지 확인하는 것은 마케팅 목적 에 따른 의사결정을 수립하는 데 도움이 될 것이다. 아울러, 이 연구에서는 스포츠 팀에 대한 팬의 신뢰가 행동에 미치는 영향을 조절하는 변수로 팀 동일시의 효과를 검증하고자 한 다. 팀 동일시는 스포츠 경영학 연구에서 소비자 행동을 예측 하는 핵심 변인이다. 이 연구에서는 팀이 패배한 상황에서 구 단에 대한 스포츠팬의 신뢰가 이후 행동의도에 미치는 영향 을 조절하는 주요 요인일 것이라고 예상하였다. 팀 동일시는 스포츠팬의 패배경험 이후에도 자신이 가진 신뢰가 향후 전 환의도와 재관람의도에 미치는 영향을 조절할 것이다.

이 연구의 목적은 응원하는 팀 패배 이후 스포츠팬이 가진 구단에 대한 신뢰가 향후 행동에 미치는 영향을 팀 동일시가 어떻게 조절하는지 확인하는 것이다. 신뢰의 특성에 따라 세 부적으로 개념을 분류하고 세부개념이 패배 후 스포츠팬 행 동에 어떤 영향을 미치는지 파악하는 것은 스포츠 소비자 연 구에서 신뢰의 역할의 이론적 확장과 실무적 활용성을 높이 는 의미가 있을 것이다.

\section{경기 결과가 스포츠 팬 감정에 미치는 영향}

소비자 의사결정은 주로 인지적 측면을 중심으로 연구해 왔으나 최근에는 감정 역시 의사결정에 중요한 영향을 미치 는 것으로 보고하고 있다(Loewenstein, Weber, Hsee, \& Welch, 2001). 제품 구매에서 발생한 부정적 감정이 불평 행동에 영향을 미치기 때문이다(Wesbrook \& Oliver, 1991), 특히 후회감과 실망감은 인간 의사결정에 중요한 역 할을 하는 것으로 밝혀졌다(Creyer \& Ross, 1999; Inman \& McAlister, 1994). Biscaia (2015)에 따르면 스포츠 관 람객은 관람 도중 기분 좋은 감정(Joy, Enjoyment)이나 불 쾌한 감정(Anger, Dejection)을 경험 할 수 있는데 이러한 감정의 종류에 따라 스포츠팬의 향후 관람의도와 추천의도 가 달라진다. 따라서 패배로 인한 스포츠 팬 감정 역시 소비 자 행동을 예측하는데 중요한 역할을 한다.
경기 결과에 따른 팬 감정에 대한 연구는 스포츠 경영학 분야에서 꾸준히 지속되어 왔다. 긍정적 경기 결과는 팬의 긍정적 감정으로 이어지고(Gratitude, Pride : Madrigal, 2008) 만족도(Van Leeuwen, Quick, \& Daniel, 2002), 즐거움(Wann \& Schrader, 1997), 에 긍정적 영향을 미친 다. 반대로 부정적 경기결과는 부정적 감정(Shame , Anger : Madrigal, 2008)을 유발한다. Wann \& Branscombe (1992)는 팀 동일시 수준에 따라 스포츠소비 자의 감정반응이 다르게 나타나는 것을 연구하였다. 구체적 으로, 높은 수준의 동일시를 가진 팬은 응원하는 팀이 패배 하였을 때 낮은 수준의 동일시를 가진 팬보다 부정적 감정을 강하게 느꼈다. Wann \& Schrader (1997)의 연구에서는 관람객의 즐거움 정도가 홈 팀의 승리와 패배에 따라 달라졌 다. 또한 팬들이 가진 동일시에 따라 즐거움 정도가 달라졌 다. 높은 수준의 동일시를 가진 팬 그룹이 응원하는 팀의 승 리에 가장 높은 수준의 즐거움을 느끼는 것으로 나타났다. Kim, Magnusen, \& Lee (2017)는 스포츠 경기에서 발생 하는 실망스러운 승리(Disappointing win)와 견딜만한 패 배(Relieving loss)에서 스포츠팬이 혼합된 감정(Mixed emotion)을 느끼는 것을 연구하였다. 스포츠팬은 경기 결 과에 따라 행복감과 슬픔이 좌우되지만 게임 내용이 어땠는 지에 따라 관람 후 슬픔이 완화되거나 행복감이 상승하는 것 을 확인할 수 있다. Yim \& Byon (2018)은 스포츠 경기에 서 패배를 서비스 실패로 보았다. 그들은 감정-만족-행동 모형(Emotion-Satisfaction-Behavior Model)을 통해 게임의 승패와 상관없이 당시 스포츠팬이 느끼는 긍정적 감 정은 경기 만족도와 서비스 만족도에 정적인 영향을 미치 며, 부정적 감정은 부적인 영향을 미치는 것을 확인하였다. 또한 게임에 대한 만족도는 재관람의도와 머천다이즈 구매 의도에 긍정적 영향을 미쳤다. 이를 통해 경기 패배로 인해 스포츠팬은 부정적 감정을 느끼고, 이는 스포츠 소비자 행 동에 영향을 미치는 것을 알 수 있다(Jang, Ko, Wann, \& Chang, 2017; Yoshida \& James, 2010).

\section{경기 결과가 스포츠 팬 행동에 미치는 영향}

스포츠팬들은 승리한 팀은 더 응원하고(BIRGing) 패배한 팀에 대한 응원을 줄이는(CORFing) 행동을 보인다 (Cialdini \& Richardson, 1980). 이러한 행동 경향성은 게 임 결과가 스포츠 팬 행동에 영향을 미치는 근거가 된다. 
Madrigal \& Chen (2008)은 스포츠팬의 팀 동일시 수준이 어떻게 경기 결과에 대한 귀인(Attribution)을 조절하고 매 개하는지에 대해 연구하였다. 그들은 NFL 시청자 121 명을 대상으로 연구를 진행했다. 이들의 연구에서 스포츠팬은 게 임에서 이겼을 때 더 높은 만족도를 보였다. 또한, 팀동일시 가 강한 팬일수록 승리의 원인을 내부에 귀인 했으며 더 많 이 반사된영광누리기(BIRG)를 하는 것으로 나타났다. 하지 만 팀동일시가 약한 팬이 더 외부요인에 귀인 하는 결과는 나 타나지 않았다.

Jang, Ko, Wann, \& Chang (2017)은 스포츠 경기가 소 비자 행동에 미치는 주요 요인을 게임결과와 게임과정으로 보았다. 해석수준이론(Construal Level Theory : Trope \& Liberman, 2003)과 행위자-관찰자 이론(Actor-Observer Theory : Nisbett. Caputo, Legant, \& Marecek, 1973) 이론을 근거로 스포츠 관람객들은 게임과정보다는 게임결과 에 집중할 것이라고 예상하였다. 이들은 아마존 Mechanical turk를 활용하여 167 명의 참여자를 모집하였 다 (Study 1). 연구결과 참여자들은 긍정적 결과가 나왔을 때 만족도와 재관람의도가 더 높았으며, 긍정적인 과정일 때, 부 정적인 과정보다 만족도와 재관람의도가 더 높았다. 또한 260명을 대상으로 진행된 두 번째 연구에서는 게임 과정보 다는 결과를 더 잘 회상하는 것으로 나타났다. 또한, 타인과 경기를 함께 볼 때는 결과보다 과정에 집중하는 것으로 나타 났다. 특히 경기결과는 부정적이지만 긍정적 과정집단에서 소비경험을 평가할 때, 혼자 경기를 관람한 사람보다 함께 시 청할 때 향후 관람의도와 만족도가 더 높게 나타났다.

\section{인지적신뢰(Cognitive trust)와 정서적신뢰(Affective trust)}

신뢰에 대한 정의는 다양하게 이루어지고 있다. Zucker (1986)는 신뢰가 교환관계에 관련된 모든 사람들에게 공유 되는 기대의 집합이라고 하였으며, McAlister (1995)는 타 인의 말, 행동에 기초하여 자신의 행동을 결정할 수 있는 자 신감과 의지라고 하였다. Rousseau, Sitkin, Burt, \& Camerer (1998)는 신뢰를 다른 이의 의도나 행동에 대한 긍정적 기대를 바탕으로 자신의 취약성을 수용하려는 의도 라고 하였다. 특히 McAllister (1995)는 신뢰를 인지기반신 뢰(Cognitive-based trust)와 정서기반신뢰(Affectivebased trust)로 분류하였다. 나아가 Lewicki \&
Tomlinson (2003)은 인지적으로 예측 가능한 판단에 근거 하는 계산적 신뢰(Calculus-based trust)와 타인에 대한 배 려를 기반으로 정서적으로 형성되는 동일시 기반 신뢰 (Identification-based trust)로 구분하였다. 두 연구에서 분류한 신뢰의 명칭은 다르지만, 인지적인 판단과 정서적 유 대감을 근거로 신뢰를 분류하였음을 알 수 있다. 인지적신뢰 는 인지과정을 기반으로 형성되는 객관적 평가과정이다. 따 라서 인지적신뢰는 구체적으로 관찰 가능한 정보를 이성적, 합리적 정보처리 과정을 통해 상대방의 수행능력을 평가함 으로써 형성된다(Zur, Leckie, \& Webster, 2012). 반면 정 서적신뢰는 상호배려를 통한 사회적 교환을 통해 형성되며 상대방과의 관계나 소속감에 대한 주관적이고 감정적인 믿 음이라고 볼 수 있다(Zur et. al., 2012).

스포츠경영학 분야에서 팬과 구단의 신뢰에 대한 연구는 팬과 구단의 관계의 질(Relationship quality) 하위요소로 주로 연구되었다(Magnusen, Kim \& Kim, 2012; Kim \& Trail, 2011). Kim \& Trail (2011)은 개인과 개인의 관계뿐 만 아니라 기업과 개인의 신뢰가 존재한다고 주장한 Garbino \& Johnson (1999)의 논의를 팬과 구단의 관계로 확장하였다. 이들에 따르면, 팬과 구단의 신뢰관계는 기업과 소비자의 관계처럼 소비자가 다른 사람을 신뢰하는 방식과 비슷하게 스포츠 구단을 신뢰하는 것이다.

\section{연구모형 및 가설설정}

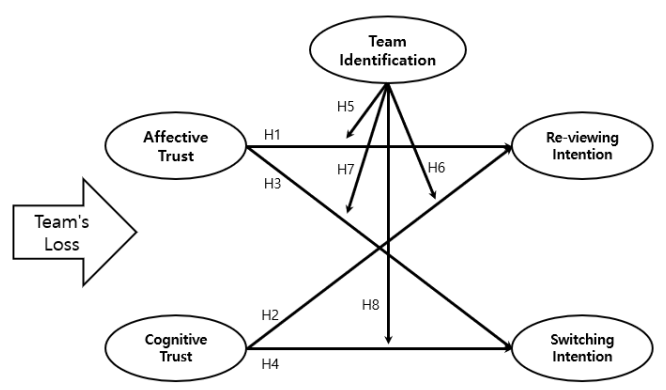

Fig. 1. The proposed hypothetical model

1) 신뢰와 재관람의도의 관계

Keh \& Xie (2009)는 B2B 맥락에서 기업에 대한 소비자 의 신뢰가 구매의도와 몰입(Commitment), 동일시 (Identification), 가격 프리미엄에 긍정적 영향을 미친다 는 것을 확인하였다. Becerra \& Korgaonkar (2009)는 공 
급자에 대한 신뢰, 브랜드에 대한 신뢰 그리고 제품에 대한 신뢰가 구매의도에 어떤 영향을 미치는지 확인하였다. 연구 결과 공급자에 대한 신뢰는 제품 구매의도로 이어졌으며, 브랜드에 대한 신뢰 역시 제품 구매의도로 이어졌다. Qureshi et al. (2009)은 온라인 구매상황에서 공급자에 대한 신뢰가 재구매의도에 영향을 미치는 것을 확인하였다. 또한, Jo (2015)에 따르면 인터넷 창업 패션 쇼핑몰 이용고 객의 신뢰는 이용 고객의 관계지속의도에 긍정적 영향을 미 쳤다. $\operatorname{Kim} \& \operatorname{Kim}$ (2016)의 연구에 따르면 학부모의 수영 장에 대한 신뢰는 지속이용의도에 유의미한 영향을 미쳤다. 이러한 연구결과에 근거하여 신뢰는 스포츠팬이 불확실한 상황에서 스포츠 팀과의 관계를 지속해 나가려는 의지를 높 일 것이며 결국, 스포츠팬의 신뢰는 재관람의도에 긍정적 영향을 미칠 것이다.

가설 1: 스포츠팬의 팀에 대한 인지적신뢰는 재관람의도 에 긍정적 영향을 미칠 것이다.

가설 2: 스포츠팬의 팀에 대한 정서적신뢰는 재관람의도 에 긍정적 영향을 미칠 것이다.

\section{2) 신뢰와 전환의도의 관계}

전환의도(Switching intention)는 고객이 자발적 또는 비자발적으로 공급자와 관계를 중단하고자하는 의도를 의 미한다(Zeelenberg \& Pieters, 2004). 전환의도는 상품이 나 서비스 제공자로부터 발생한 부정적 감정의 결과이며, 현재 상품이나 서비스 제공자를 다른 대안상품이나 서비스 로 전환할 가능성이라고 할 수 있다(Han, Kim \& Hyun, 2010). Keaveney (1995)는 고객이 기업을 전환하는 요인 으로 핵심서비스 실패, 서비스 접점실패, 서비스 실패에 대 한 반응 등을 제시했다. 그에 따르면, 소비자는 자신의 욕구 를 충족시킬 수 있는 여러 대안을 파악하고 가장 많은 효용 을 줄 것으로 예상되는 상품을 선택한다. 전환의도는 소비 자의 다양한 추구요인과 불만족 요인으로부터 표출된다고 할 수 있다(Kotler, Bowen \& Makens, 2006). 소비자의 공급자에 대한 비우호적 감정이 높을수록 다른 상품이나 공 급자로 전환할 가능성이 높아진다(Zeithaml, Berry, \& Parasuraman, 1996). Zeelenberg \& Pieters (2007)는 소비자가 제공된 서비스에 불만족할수록 전환행동의 빈도 가 높아지며, 전환행동이 용의한 서비스 환경에서는 이러한 현상이 더욱 두드러진다고 하였다.
Sweeney \& Swait (2008)는 브랜드 신용(Brand Credibility)이 신뢰성(Trustworthiness)과 전문성 (expertise)으로 구성되어 있다고 보았다. 브랜드 신용은 만 족도(Satisfaction)와 몰입(Commitment : Loyalty Commitment, Continuance commitment)을 통해 전환 의도에 부적인 영향을 미치는 것을 확인하였다. 특정 기업의 전문성과 신뢰성을 바탕으로 소비자 행동이 달라지는 것은 인지적신뢰와 정서적신뢰의 기본 개념과 상당히 유사하다. 따라서 이 연구에서는 다음과 같은 가설을 설정하였다.

가설 3: 스포츠팬의 팀에 대한 인지적신뢰는 전환의도에 부정적 영향을 미칠 것이다.

가설 4: 스포츠팬의 팀에 대한 정서적신뢰는 전환의도에 부정적 영향을 미칠 것이다.

\section{3) 팀동일시의 조절효과}

사회정체성이론(Social Identity Theory)에 바탕을 두 고 있는 동일시는 개인이 조직의 구성원으로서 조직과 성패 를 함께함으로써 자신과 조직을 공동 운명체로 인식하는 것 이다(Mael \& Ashforth, 1992). 팀동일시는 그동안 스포츠 팬 행동을 설명하는 중요 요인으로 주목받아 왔다. Kwon (2011; 2019)는 팀동일시의 이론적 역할과 정당성에 관해 연구하였다. 그는 스포츠 경영학 분야에서 팀동일시가 주도 적으로 활용되고 있음에도 불구하고 명확한 이론적 논의가 이루어지지 않고 있음을 지적하였다. 특히 사회정체성이론 에 기반을 둔 팀동일시의 개념이 스포츠분야에서 활용되는 것이 적합한가에 대해 논의하였다(Kwon, 2019). 그런 측 면에서, 팀동일시가 과연 고객-공급자의 관계에서 발생하 는 것인지 조직을 위해 일하는 동일한 사회정체성을 공유하 는 관계인지에 대해서는 더 논의가 필요하다. 이 연구에서 는 팀동일시를 사회정체성이론에 기반을 두고 변인으로 설 정하였다. Lock \& Heere (2017)에 따르면, 이 연구에서 활 용된 팀동일시 문항은 역할정체성에 기반을 두고 있다. 하 지만 Kwon (2019)에 따르면, Lock \& Heere (2017)의 역 할정체성이론과 사회정체성이론의 구분은 분석 수준의 차 이를 고려한 것이며 사회정체성 이론 역시 집단 안에서 개인 을 설명하는 것이므로 엄밀하게 구분 짓기 어렵다. 따라서, 패배 이후 신뢰가 소비자 행동에 미치는 영향에 팀동일시가 어떤 영향을 미칠지를 판단함에 있어 이론적 배경과 선행 연 구들을 함께 고려하여 결정하였다. 
응원하는 팀에 대해 동일시가 높은 스포츠팬은 팀이 패배 하더라도 동일시 수준은 변함이 없었다(Ashforth \& Mael, 1989). 팀동일시가 높은 팬은 낮은 팬들에 비해 경기 관람 횟수 및 경기에 관한 관심이 높았다(Schurr, Wittig, Ruble \& Ellen, 1988). 팀동일시는 소비자 행동을 설명하는 핵심 요인인 만큼 다양한 맥락에서 연구되었다. 팀동일시가 높은 팬은 선호하는 구단 제품과 경기를 일반 팬보다 더 적극적으 로 구매했다(Fisher \& Wakefield, 1998; Wakefield \& Sloan, 1995).

Kwon \& Choi (2018)의 팀동일시에 대한 메타분석에 따르면, 팀동일시는 관람의도, 제품구매 등에 영향을 미치 는 독립변인이다. 구체적으로, $\operatorname{Kim}$ (2010)의 연구에 따르 면 프로야구 팬의 팀동일시는 재관람의도에 긍정적 영향을 미쳤다. Kim, Lee, \& Lee (2003)의 연구에서 역시 프로축 구 팀에 대한 팬의 팀동일시는 관람의도에 정적인 영향을 미 쳤다. $\mathrm{Ha}$ (2010)의 대학 농구팀 팬에 관한 연구에서도 팀동 일시는 재관람의도에 긍정적 영향을 미치는 것으로 나타났 다. Kim, Kim, \& Hur (2010)의 프로농구구단에 팬에 관 한 연구에서 동일시는 관람의도에 정적인 영향을 미쳤다. Seo \& Kwon (2020)의 프로스포츠 팬 연구에서도 팀동일 시는 경기관람의도에 긍정적 영향을 미쳤다. 반면, 팀동일 시를 독립변인과 종속변인을 조절하는 요인으로 보는 연구 역시 다수 발행되고 있다(Kim, Han, \& Ko, 2019; Noh, Han, \& Kwon, 2013; Park, Won, \& Cho, 2013). Park et al. (2013)의 프로야구 팬의 관람제약 요인에 관한 연구에서 팀동일시는 시설요인, 선수단요인과 재관람의도 의 관계를 조절하였다. Noh et al. (2013)의 프로스포츠 구 단의 CSR활동이 구단이미지에 미치는 영향에 관한 연구에 서 팀동일시는 CSR활동과 팀 이미지의 관계를 조절하는 것 으로 나타났다. Kim et al. (2019)의 프로야구 구단의 CSR 활동에 관한 연구에서 팀동일시는 CSR활동이 팀 이미지에 미치는 영향을 조절하였다.

다양한 연구에서 팀동일시는 독립변수, 조절변수로서 역 할을 하는 것으로 나타났다. 그동안 스포츠 경영학 연구에 서 팀동일시는 팀과 스포츠팬의 일체감을 설명하는 요인으 로 연구됐다. 팀에 대한 스포츠 팬의 동일시는 경기 결과에 따라 변할 수 있다. 하지만, 경기를 관람하기 전 가지고 있는 팀 동일시는 기존에 맺고 있던 구단과의 관계를 반영하는 것 으로 경기 결과와는 아무 관계가 없다. 따라서 이 연구에서 의미하는 팀동일시는 기존에 팬이 가지고 있는 구단에 대한
신뢰가 패배 이후 소비자 행동에 미치는 영향을 조절하는 역 할을 할 것으로 본다. 이 연구에서는 패배로 인해 스포츠팬 의 신뢰나 팀 동일시가 변화하는 것이 아닌, 스포츠팬이 경 기 관람 전에 가지고 있는 신뢰와 동일시가 재관람의도와 전 환의도에 영향을 미친다고 보았다. 따라서, 팀동일시를 조 절변수로 보는 것이 더 적합하다고 판단하였다.

이러한 선행연구 결과들을 바탕으로 팀 동일시 수준에 따 라서 인지적신뢰와 정서적신뢰가 소비행동의도에 미치는 영향이 달라질 것이라고 제안한다. 특정 대상의 능력이나 친근감에 대한 믿음은 누구나 가질 수 있다. 하지만 팀에 대 한 애착이나 일체감이 높은 팬일수록 전환행동은 낮아지고, 재관람의도는 높아질 것이다.

가설 5: 팀 동일시가 높은 스포츠팬은 팀에 대한 인지적 신뢰가 재관람의도에 미치는 영향이 팀동일시가 낮은 그룹에 비해 더 높게 나타날 것이다.

가설 6: 팀 동일시가 높은 스포츠팬은 팀에 대한 정서적 신뢰가 전재관람의도에 미치는 영향이 팀동일시 가 낮은 그룹에 비해 더 높게 나타날 것이다.

가설 7: 팀 동일시가 높은 스포츠팬은 팀에 대한 인지적 신뢰가 전환의도에 미치는 영향이 팀동일시가 낮은 그룹에 비해 더 낮게 나타날 것이다.

가설 8: 팀 동일시가 높은 스포츠팬은 팀에 대한 정서적 신뢰가 전환의도에 미치는 영향이 팀동일시가 낮은 그룹에 비해 더 낮게 나타날 것이다.

\section{연구방법}

\section{연구대상}

아마존 Mechanical Turk를 이용해 주기적으로 미국 남 자 축구 국가대표 경기를 관람하는 미국인을 모집단으로 설 정하여 연구를 진행했다. 응답의 신뢰도를 높이기 위해 5,000 회 이상 승인을 받고 승인율이 $95 \%$ 이상인 미국 거주 자만 참여할 수 있도록 설정했다. 설문조사는 2020년 10월 26 일부터 10월 27일까지 진행했다. 표집방법은 비확률 표 본추출법(non-probability sampling method)중 편의표 본추출법(convenience sampling method)을 활용하였 
다. 구체적으로, 인터넷 설문조사는 세 단계로 구성했다. 향 후 주어질 패배 메시지(Fig. 2)에 의한 신뢰 변화를 방지하 기 위해 첫 번째 단계에서 참여자들의 미국 남자축구대표팀 에 대한 인지적, 감정적 신뢰, 팀 동일시를 측정하였다. 그 후 미국 남자축구대표팀이 멕시코 대표팀에게 패배했다는 메시지를 제시하였다. 마지막으로 연구 참여자들은 미국 남 자 축구대표팀 경기 재관람의도와 전환의도에 대한 질문에 응답하였다. 연구 참여자들에게는 50센트를 참여 보상으로 지급하였다.

수집된 총 300 부의 설문 중 불성실한 응답을 한 것으로 판단되거나 응답시간이 매우 짧은(30초) 응답 12 부를 제외 한 288부를 최종적으로 연구에 사용했다. 연구 참가자의 인 구통계학적 특성은 〈Table 1)과 같다. 응답자들의 평균 응 답시간은 253 초였으며, 평균 연령은 36.12세 (SD=9.44)로 나타났다.

Table 1. Demographic characteristics $(n=288)$

\begin{tabular}{|c|c|c|c|}
\hline & Variables & $\mathrm{n}$ & Frequency $(\%)$ \\
\hline \multirow{2}{*}{ Gender } & Male & 198 & 68.8 \\
\hline & Female & 90 & 31.2 \\
\hline \multirow{4}{*}{ Age } & $20-29$ & 76 & 26.4 \\
\hline & $30-39$ & 125 & 43.4 \\
\hline & $40-49$ & 59 & 20.5 \\
\hline & $50 \leq$ & 28 & 9.7 \\
\hline \multirow{4}{*}{ Education } & High school & 51 & 17.7 \\
\hline & College & 172 & 59.7 \\
\hline & Graduate school & 62 & 21.5 \\
\hline & Do not want to answer & 1 & 0.3 \\
\hline \multirow{7}{*}{ Race } & Caucasian & 120 & 41.7 \\
\hline & African-American & 66 & 22.9 \\
\hline & Ratin or Hispanic & 41 & 14.2 \\
\hline & Asian & 22 & 7.6 \\
\hline & Native American & 39 & 13.5 \\
\hline & More than two & 5 & 1.7 \\
\hline & Others & 1 & 0.3 \\
\hline
\end{tabular}



Fig. 2. Team loss stimuli

\section{조사도구}

연구 참여자는 자기평가기입법(self-administration method)으로 설문에 응답하였다. 설문항목은 모두 7점 리 커트타입 척도로 구성되었다. 구체적 내용은 다음과 같다.

인지적신뢰와 감정적신뢰는 McAllister (1995)의 연구 에서 사용된 인지적신뢰 4문항, 정서적신뢰 4문항을 사용하 였다. 스포츠 관람 맥락에 어울리지 않는 문항을 제외하였으 며, 나머지 문항은 스포츠 상황에 맞게 적용하여 사용하였 다. 팀 동일시는 Wann \& Branscombe (1993)의 연구에서 활용된 문항을 사용하였다. 재관람의도는 Cunningham \& Kwon (2003)의 연구에서 사용한 문항을 참고하여 4 문항으 로 구성하였으며, 전환의도는 Keaveney (1995)의 연구에 서 사용된 문항을 스포츠 관람맥락에 맞게 수정하여 4문항 으로 구성해 사용했다. 연구에 사용한 측정도구들은 선행연 구에서 신뢰도, 판별타당도, 수렴타당도가 모두 적합하게 나 타났으며, 스포츠 경영학 교수 1 명과 원어민 박사과정 1 명 을 포함한 박사과정 2 명이 수차례 회의를 거쳐 안면타당도 와 내용타당도를 확보하였다.

\section{자료처리방법}

자료처리는 SPSS 21.0과 Mplus 8을 사용해 분석했다. SPSS 21.0 을 이용해 기술통계분석, 빈도분석과 신뢰도 분석을 실시했다. Mplus 8을 이용해 확인적 요인분석(confirmatory factor analysis), 경로분석과(path analysis), 잠재조절구조 
방정식(latent moderated structural equation modeling) 분석을 실시했다.

Table 2. Inter-construct correlations and square-root of AVE

\begin{tabular}{lccccc}
\hline \hline & 1 & 2 & 3 & 4 & 5 \\
\hline 1. Cognitive trust & .85 & & & & \\
\hline 2. Affective trust & .68 & .87 & & & \\
\hline 3. Reviewing intention & .51 & .51 & .88 & & \\
\hline 4. Switching intention & -.20 & -.14 & -.42 &. $\mathbf{8 9}$ & \\
\hline 5. Team Identification & .49 & .51 & .85 & -.16 & $\mathbf{. 8 5}$ \\
\hline \hline
\end{tabular}

\section{연구결과}

\section{조사도구 타당도 및 신뢰도}

연구에 사용된 측정 문항 신뢰도와 타당도를 확인하기 위 해 신뢰도 분석과 확인적 요인분석을 실시하였다. 그 결과는 〈Table 3〉과 같다.

모형 적합도는 $x^{2}=211.46(\mathrm{df}=80, \mathrm{p}<.05), \mathrm{x}^{2} / \mathrm{df}=2.64$, RMSEA는 .07, TLI는 .95, NFI는 .94, CFI는 .96, SRMR은 .03 으로 적합한 것으로 나타났다. 구성개념의 신뢰도는 모 두 .7이상 ( $a=.89$.92)의 신뢰수준을 보였다(Nunnally \& Bernstein, 1994). 구성개념의 평균분산추출값(AVE)은 모 두 .7이상으로 구성개념 수렴타당성을 확보했다(Fornell \& Larcker, 1981). 판별타당도를 확인하기 위해 각 개념의 제 곱근 $\mathrm{AVE}$ 값이 각 개념 간의 상관계수보다 큰 것으로 나타 나 판별타당도가 확보되었다고 볼 수 있다(Fornell \& Larker, 1981). 하지만 팀 동일시와 관람의도의 상관계수와 제곱근 AVE값의 차이가 .02로 나타났다. 따라서 판별타당 성을 검증하는 다른 방법인 구성개념 간 상관관계를 1.0 로 제약한 모형과 상관관계를 자유롭게 추정한 모형의 적합도 를 카이제곱 검정을 통해 비교했다. 이를 모든 구성개념에 실시한 결과, 두 모형의 카이제곱 값의 차이가 임계치인 3.84(df=1, p= .05; Tabachnick \& Fidell, 2007)보다 큰
것으로 나타났다. 이 결과는 두 모형의 적합도가 통계적으로 유의미한 차이가 있는 것을 의미한다. 이를 통해 어떠한 구 성개념 간에도 완전상관관계(perfect correlation)가 있지 않음을 통계적으로 뒷받침하며, 측정모형의 판별타당성이 확보되었음을 의미한다(Anderson \& Gerbing, 1988).

독립변인과 종속변인을 자기기입법에 의해 측정하는 방 식의 연구에서 발생할 수 있는 동일방법편의(common method bias)를 확인하기 위해 Harman의 단일요인 검정 (single-factor test)을 실시했다. 그 결과 단일잠재변인이 측정 총 분산의 $46.10 \%$ 을 설명하여 Podsakoff (2003)이 제시한 기준인 $50 \%$ 보다 낮아 동일방법편의가 연구결과에 심각한 영향을 미치지는 않을 것으로 나타났다.

데이터의 정규성을 검증하기 위해 각 변인의 왜도 (skewness) 및 첨도(kurtosis)를 검토했다. 그 결과, 왜도는 최소 -.42에서 최대 .91로 나타났으며, 첨도는 최소 -.95에 서 최대 .22로 확인됐다. 이러한 결과는 왜도와 첨도의 절댓 값이 2 를 넘지 않는 경우 정규분포 형성을 수용할 수 있다는 George \& Mallery (2010)의 기준을 충족한다. 또한, 히스 토그램과 Q-Q 그래프를 확인한 결과 정규분포의 형상을 띄 는 것으로 나타났다. 따라서 이 연구에서 수집된 관측 변인 들이 수용 가능한 수준의 정규분포를 형성하고 있는 것으로 평가했다.

\section{경로분석}

설정된 각 변인 간 관계를 분석한 결과 〈Table 4〉와 같은 결과를 얻었다. 모형 적합도는 $\mathrm{x}^{2}=124.73(\mathrm{df}=49, \mathrm{p}<.05)$, $\mathrm{x}^{2} / \mathrm{df}=2.74$, RMSEA .07, TLI .96, NFI .95, CFI .97, SRMR은 .08로 만족할만한 적합도를 보였다.

경로분석 실시 결과 가설 1 인지적신뢰가 스포츠 팬의 재 관람의도에 미치는 영향에 대한 가설검증 결과 $(\gamma=.31$ $\mathrm{p}$ (.05) 통계적으로 유의미한 결과를 보였다. 따라서 가설 1 은 지지되었다. 가설 2 정서적신뢰가 스포츠팬의 재관람 의도에 미치는 영향에 대한 가설검증 결과 $(\gamma=.29 \mathrm{p}<. .05)$ 통계적으로 유의미한 결과를 보였다. 가설 2는 지지되었다. 가설 3 인지적신뢰가 스포츠팬의 전환의도에 미치는 영향 은 통계적으로 유의미하게 나타났다 $(\gamma=-.21 \mathrm{p}<. .05)$ 가설 3 은 지지되었다. 가설 4 정서적신뢰가 스포츠팬의 전환의 도에 미치는 영향은 통계적으로 유의미한 결과를 보이지 않 았다 $(\gamma=-.00 \mathrm{p}=.93)$. 따라서 가설 4는 기각되었다. 
Namkyeong Jang et al.

Table 3. Result of the confirmatory factor analysis

\begin{tabular}{|c|c|c|c|c|c|}
\hline Dimension & Items & Standard coefficients & C.R & AVE & a \\
\hline \multirow{3}{*}{$\begin{array}{l}\text { Cognitive } \\
\text { Trust }\end{array}$} & Most people trust and respect the US Men's National Soccer Team & .86 & \multirow{3}{*}{.89} & \multirow{3}{*}{.73} & \multirow{3}{*}{.8} \\
\hline & $\begin{array}{l}\text { The US Men's National Soccer Team can be trusted because their } \\
\text { abilities are exceptional }\end{array}$ & .88 & & & \\
\hline & $\begin{array}{l}\text { I believe the US Men's National Soccer Team will be successful at the } \\
2022 \text { FIFA world cup }\end{array}$ & .83 & & & \\
\hline \multirow{3}{*}{$\begin{array}{l}\text { Affective } \\
\text { Trust }\end{array}$} & The US Men's National Soccer Team is interested in fans' opinions & .88 & \multirow{3}{*}{.90} & \multirow{3}{*}{.75} & \multirow{3}{*}{.90} \\
\hline & $\begin{array}{l}\text { The US Men's National Soccer Team is attentive to the feelings and } \\
\text { emotions of the fans }\end{array}$ & .81 & & & \\
\hline & $\begin{array}{l}\text { The fans can freely voice their opinions and concerns about the US } \\
\text { Men's National Soccer Team and I know they will want to listen }\end{array}$ & .91 & & & \\
\hline \multirow{3}{*}{$\begin{array}{l}\text { Reviewing } \\
\text { Intention }\end{array}$} & $\begin{array}{l}\text { I will continue to watch US Men's National Soccer team's games in the } \\
\text { future }\end{array}$ & .91 & \multirow{3}{*}{.91} & \multirow{3}{*}{.78} & \multirow{3}{*}{.92} \\
\hline & I am willing to watch the US Men's National Soccer team's game & .86 & & & \\
\hline & I will try to watch a US Men's National Soccer team game & .89 & & & \\
\hline \multirow{3}{*}{$\begin{array}{l}\text { Switching } \\
\text { Intention }\end{array}$} & I will not give support for the US Men's National Soccer team & .92 & \multirow{3}{*}{.92} & \multirow{3}{*}{.80} & \multirow{3}{*}{.92} \\
\hline & $\begin{array}{l}\text { For the time being, I will not watch the US Men's National Soccer } \\
\text { team's matches }\end{array}$ & .88 & & & \\
\hline & I don't want to think about the US Men's National Soccer team & .89 & & & \\
\hline \multirow{3}{*}{$\begin{array}{c}\text { Team } \\
\text { Identification }\end{array}$} & I already consider myself a fan of US Men's National Soccer team. & .86 & \multirow{3}{*}{.89} & \multirow{3}{*}{.73} & \multirow{3}{*}{.89} \\
\hline & $\begin{array}{l}\text { I would feel a loss if I had to give up being a US Men's National } \\
\text { Soccer team fan. }\end{array}$ & .85 & & & \\
\hline & Others recognize that I am a big US Men's National Soccer team fan. & .86 & & & \\
\hline
\end{tabular}

\section{팀 동일시의 조절효과}

구조방정식 모형에서 조절변수를 분석하는 방법은 변수 의 집단 구분을 통해 분석하는 다중집단분석(Multi-Group analysis)와 잠재조절구조방정식이 있다(Latent Moderated Strucural Equation Modeling). 본 연구에 서는 잠재조절변인으로서 팀 동일시가 인지적·정서적신뢰 가 재구매의도와 전환의도에 미치는 영향을 조절하는지 확 인하기 위해 잠재조절구조방정식을 활용하였다. 평균이나 중간값을 통해 그룹을 나눈 그룹 간 비교가 아닌 팀 동일시
의 연속변수 속성을 유지했다. 이는 연속변수의 그룹화가 임의적이기 때문에 이론적 근거가 부족하며 많은 정보 손실 로 인한 통계적 파워를 낮춤으로써 일종오류가 발생 가능성 을 높일 여지가 있기 때문이다(Fitzsimons, 2008; Irwin \& McClelland, 2003).

잠재조절구조방정식 모형의 적합도는 2 단계 평가 방법 을 실시하는데, 이는 잠재상호작용 요인을 포함하지 않은 첫 번째 모형(Model0)과 잠재상호작용 요인을 포함한 두 번째 모형을 추정한다(Klein \& Moosbrugger, 2000). 첫 번째 단계에서는 잠재상호작용 요인을 포함하지 않은 모형 
의 적합도 지수를 평가한다. 두 번째 단계에서는 잠재상호 작용 요인을 포함한 모형과 포함하지 않은 모형의 우도비 (Log-liklihood) 값을 비교한다(Klein \& Moosbrugger, 2000). 우도비(Log-likelihood) 비교를 통해 상호작용을 포함한 모형의 값이 더 우수하다면 이를 채택할 수 있다. 잠 재 상호작용요인을 포함하지 않은 모형의 적합성은 앞서 만 족할만한 것으로 나타났다. 이에 따라, 우도비 검정 (Log-liklihood ratio test)을 실시하였다. 그 결과 상호작 용항을 삽입한 모형이 통계적으로 우월한 것으로 나타났다 $(\mathrm{D}=29.19, \triangle \mathrm{df}=5)$

조절효과 분석결과 인지적신뢰와 팀 동일시의 상호작용
항은 재관람의도에 통계적으로 유의미한 영향을 미치지 못 했다 $(\gamma=.07 \mathrm{p}=.14)$. 정서적신뢰와 팀 동일시의 상호작용 항 역시 재관람의도에 유의미한 영향을 미치지 못했다 $(\gamma=$ $.03 \mathrm{p}=.52)$. 이는 두 변수가 재관람의도에 미치는 영향을 팀 동일시가 조절하지 못함을 의미한다. 따라서 가설 5 와 6 은 기각되었다. 인지적신뢰와 팀 동일시의 상호작용항은 전 환의도에 통계적으로 유의미한 영향을 미치지 못했다 $(\gamma=$ -.08 p=.30). 따라서 가설 7은 기각되었다. 정서적신뢰와 팀 동일시의 상호작용 항은 전환의도에 유의미한 영향을 미 쳤다. 따라서 정서적신뢰와 전환의도의 관계를 팀 동일시가 조절한다고 예상하였던 가설 8은 채택되었다.

Table 4. The results of hypotheses testing

\begin{tabular}{cccccc}
\hline \hline & Path & Standard coefficients & Standard error & $\mathrm{t}$ & $\mathrm{p}$ value \\
\hline $\mathrm{H} 1$ & Cognitive trust $\rightarrow$ Re-viewing intention & .31 & .08 & 3.89 & $\mathrm{p}<.05$ \\
\hline $\mathrm{H} 2$ & Affective trust $\rightarrow$ Re-viewing intention & .29 & .08 & 3.62 & $\mathrm{p}<.05$ \\
\hline $\mathrm{H} 3$ & Cognitive trust $\rightarrow$ Switching intention & -.21 & .11 & -2.27 & $\mathrm{p}<.05$ \\
\hline $\mathrm{H} 4$ & Affective trust $\rightarrow$ Switching intention & -.00 & .11 & -.08 & $\mathrm{p}=.93$ \\
\hline \hline
\end{tabular}

Table 5. Team identification's moderating effect results summary

\begin{tabular}{cccccc}
\hline \hline & Path & Standard coefficients & Standard error & $\mathrm{t}$ & $\mathrm{p}$ value \\
\hline $\mathrm{H} 5$ & Cognitive trust $\mathrm{x}$ Identification $\rightarrow$ Re-viewing intention & .07 & .05 & 1.45 & $\mathrm{p}=.14$ \\
\hline $\mathrm{H} 6$ & Affective trust $\mathrm{x}$ Identification $\rightarrow$ Re-viewing intention & .03 & .05 & .64 & $\mathrm{p}=.52$ \\
\hline $\mathrm{H} 7$ & Cognitive trust $x$ Identification $\rightarrow$ Switching intention & -.08 & .08 & -1.03 & $\mathrm{p}=.30$ \\
\hline $\mathrm{H} 8$ & Affective trust $x$ Identification $\rightarrow$ Switching intention & -.20 & .09 & -2.26 & $\mathrm{p}<.05$ \\
\hline \hline
\end{tabular}

\section{논 의}

본 연구는 패배 후 스포츠팬 행동이 신뢰에 의해 어떻게 달 라질 수 있는지 알아보는데 그 목적이 있다. 연구결과를 바탕 으로 내린 논의는 다음과 같다.

스포츠팬의 인지적신뢰는 재관람의도에 정(+)의 영향을 미쳤다. 경기에 패배하더라도 구단의 능력에 대한 신뢰가 있 는 팬은 지속적으로 경기를 관람하려는 의지를 보였다. 스포
츠팬의 정서적신뢰는 재관람의도에 정(+)의 영향을 미쳤다. 스포츠팬은 구단이 경기에 패배했더라도 구단과의 정서적 연 결을 통해 다음 경기를 관람하려는 의도를 높이는 것으로 나 타났다. 가설 1 과 2 의 결과는 신뢰가 소비자 구매의도를 향 상시키는 결과를 보여주었던 Keh \& Xie (2009), Becerra \& Korgaonkar (2009), Qureshi et al. (2009)의 연구와 일 맥상통하는 결과이다. 또한, 백화점 상품구매 시 소비자의 인 지적·정서적신뢰가 재구매의도에 긍정적 영향을 미친다고 
확인한 Park, Lee, Hong, \& Lee (2009)의 연구와 동일한 결과이며, 온라인 소비자의 만족에 대해서 연구한 Punyatoya (2019)의 연구와도 동일한 결과이다. 서비스관 계와 소비자의 인지적·정서적신뢰를 연구한 Johnson \& Grayson (2005) 역시 인지적신뢰와 정서적신뢰 모두 예상 되는 미래상호작용에 긍정적 영향을 미쳤다. 모바일 간편결 제 서비스에 대해 연구한 Choi \& Choi (2017)의 연구에서 도 인지적신뢰와 정서적신뢰는 소비자 만족도에 긍정적 영향 을 미쳤다. 기업의 사회적책임과 공유가치 창출이 소비자 충 성도에 미치는 영향에 대해 연구한 Moon \& Kim (2016)의 연구 결과에서도 인지적신뢰와 정서적신뢰는 충성도에 긍정 적 영향을 미치는 것으로 나타났다.

이러한 결과는 패배나 서비스 실패를 경험하더라도 스포 츠팬의 재관람의도를 높이기 위해 스포츠 마케터들은 인지적 신뢰와 정서적신뢰를 모두 고려한 의사결정을 해야 한다는 것을 의미한다. 팬과 지속적인 소통을 통해 인지적·정서적신 뢰 관계를 쌓아나갈 필요가 있다. 인지적신뢰를 높이기 위해 선수 영입이나 감독전술 등 팀이 가진 전력 우수성을 지속적 으로 팬들에게 노출시킬 필요가 있다. 또한 정서적신뢰 구축 을 위해 팬들의 의견에 귀 기울이고 적극적으로 소통하는 모 습을 보여줌으로써, 정서적신뢰를 쌓을 필요가 있다. 평소구 축한 신뢰를 바탕으로 경기패배라는 서비스 실패 상황에서도 팬들은 지속적인 관람의사를 보일 것이다. 이를 위해, 구단 개인 소통채널을 통한 지속적인 메시지 제공이 필요하다. 스 포츠 구단과 팬의 관계는 다소 일방적이다. 일부 구단은 이를 해소하기 위해 다양한 SNS 채널을 이용하고 있지만 인력과 예산부족으로 인해 효과적 의사소통이 이루어지고 있지 않 다. 반면, SNS에는 스포츠 구단을 어떠한 금전적 이익 없이 서포트 하는 팬들이 많다. 이들과 협업하여 구단과 팬들의 구 심점 역할을 하도록 한다면, 더욱 더 효과적으로 신뢰를 형성 할 수 있을 것이다.

스포츠팬의 인지적신뢰는 전환의도에 부(-)의 영향을 미 쳤다. 구단이 가진 능력에 대한 신뢰는 경기 패배했더라도, 스포츠팬으로 하여금 다음 경기를 기대하게 함으로써 전환의 도를 억제하는 효과가 있었다. 이는 브랜드 신용과 소비자 행 동의 관계를 연구한 Sweeney \& Swait (2008)과 동일한 연 구 결과이다.

스포츠팬의 정서적신뢰는 전환의도에 유의한 영향을 미치 지 못했다. 선행연구 중 본 연구와 유사한 연구결과가 나타나 는 연구 결과를 바탕으로 이러한 이유에 대해 논의하고자 한
다. 위 결과는 생명보험사 모집인들의 조직에 대한 인지적신 뢰는 이직의도에 부정적 영향을 미쳤지만, 정서적신뢰는 영 향을 미치지 못했다고 보고한 Cho (2017)의 연구와 동일한 결과이다. 인지적신뢰는 종속변수에 영향을 미쳤지만, 정서 적신뢰는 영향을 미치지 못한 연구들도 존재한다. $\mathrm{Ha} \&$ $\mathrm{Nam}$ (2015)의 연구에서는 인지적신뢰가 상호정보공유에 영향을 미쳤지만, 정서적신뢰는 미치지 못했다. 또한 소매점 특성과 신뢰, 충성도의 관계를 연구했던 Choi (2014)에 따 르면, 인지적신뢰는 충성도에 영향을 미쳤지만, 정서적신뢰 의 직접효과가 나타나지 않았다.

이들은 이러한 결과를 산업적 특성과 연구대상의 특성을 이유로 들어 설명하였다. 본 연구에서도 관람스포츠 소비자 의 특성으로 인해 이러한 결과가 발생한 것으로 추측된다. 첫 째, 본 연구의 대상은 미국의 국가대표 팀이었다. 따라서 관 람객은 국가로 인해 팀에 대한 정서적신뢰를 갖고 있을 가능 성이 있다. 반면에, 정서적신뢰는 감정적 연결과 공통으로 공 유하는 가치를 바탕으로 오랜 시간에 걸쳐 형성되는 특성이 있다(Ye, Hofacker, Peloza, \& Allen, 2020). 그러므로 프 로스포츠 팀처럼 오랜 기간 동안 교류하며 만들어진 정서적 신뢰가 부족할 수 있다. 이로 인해, 팀과의 정서적 교류보다 는 대리성취경험이나 승리를 통한 즐거움을 얻는 목적을 얻 고자 하는 동기가 더 컸을 수 있다(Han, Mahony, \& Greenwell, 2016; Trail \& James, 2001). 따라서 패배를 경험하였을 때, 팀에 대한 능력을 믿을 때에는 다음 경기에 이길 가능성이 있기 때문에 전환의도에 부정적 영향을 미쳤 을 것이다. 반면, 정서적신뢰는 관람자들의 관람목적이나 동 기와 일치하지 않아 유의미한 영향을 미치지 못했을 수 있다.

둘째, 정서적신뢰가 전환의도에 부정적 영향을 주기 위해 서는 충분한 시간이 필요했을 수 있다. 패배로 인한 부정적 감정으로 인한 즉각적 의사결정은 연구 참여자들이 스트레스 로부터 멀어지고자 하는 욕구를 강화시켰을 것이다 (Sengupta et al, 2015). 따라서, 설문지 법의 한계로 인해 참여자는 팀과의 정서적 관계를 고려하지 못한 채 답변했을 가능성이 존재한다. 예를 들어, 우리는 종종 가까운 누군가의 능력 부족이나 실수로 그 사람과의 관계를 정리하고 싶다는 생각이 든다. 하지만, 충분한 시간을 갖고 생각했을 때 그 사 람과의 정서적 연결성을 생각하게 되며 그러한 생각을 멈추 게 하는 기제가 된다. 이처럼 팀과의 관계를 충분히 숙고할 시간이 제공되었다면 다른 결과가 발생했을 가능성이 있다. 조절효과 분석결과 유일하게 정서적신뢰가 전환의도에 미 
치는 영향에만 팀 동일시가 조절효과를 보이는 것으로 나타 났다. 사람들은 일반적으로 자신을 평가하는데 관대하다 (Harris \& Schaubroeck, 1988). 또한 외집단보다 내집단 을 평가할 때 더 좋은 평가를 주는 경향이 있다(Tajfel, Billing, Bundy, \& Flament, 1971). 이를 바탕으로 패배하 였을 때 팀에 대한 동일시를 얼마나 높게 느끼는지에 따라 인 지적신뢰가 재관람의도와 전환의도에 미치는 영향이 조절될 것으로 생각했지만 가설 5, 6, 7은 기각되었다. Yim \& Byon (2018)에 따르면 높은 팀 동일시를 가진 팬은 낮은 동일시를 가진 팬에 비해 경기 승패에 따른 만족도가 달라지지 않았다. 이러한 결과는 팀 동일시가 높은 팬은 팀의 능력보다도 정서 적 연결성에 높은 의미를 두기 때문에 상호작용 결과가 유의 미하지 않은 것으로 추측된다.

반면, 정서적신뢰가 전환의도에 미치는 영향에 팀 동일시 는 조절효과를 보였다. Wann \& Branscombe (1990)의 연 구 결과에 따르면 높은 팀 동일시를 가진 스포츠 팬은 낮은 팀 동일시를 가진 팬에 비해 팀과의 관계를 덜 분리하는 모습 을 보였다. 이는 팀 동일시가 높을수록 패배에 따라 팀과의 연결성을 유지하려는 의도가 높아진다는 의미이다. 따라서 팀 동일시가 높은 팬일수록 정서적신뢰가 전환의도에 미치는 영향을 더 받았다고 볼 수 있다. 이러한 결과는 팀 동일시가 높은 팬은 인지적신뢰보다는 정서적신뢰가 더 중요한 요인이 라고 볼 수 있다. 따라서 동일시가 높을 것으로 예상되는 집 단에는 이에 맞는 마케팅 전략과 패배 이후 메시지 전달이 필 요하다.

\section{결론 및 제언}

이 연구는 스포츠 경기 패배로 인한 소비자 행동에 인지적 신뢰와 정서적신뢰가 어떤 영향을 미치는지 확인하였다. 구 체적으로, 인지적신뢰와 정서적신뢰가 재관람의도와 전환 의도에 각각 어떤 영향을 미치는지 구조방정식모형을 통해 확인하였다. 또한 스포츠 팬이 가진 팀에 대한 동일시가 신 뢰가 소비자 행동에 미치는 영향을 조절하는지 확인하였다.

인지적신뢰는 응원하는 팀의 경기패배 후 스포츠팬의 재 관람의도에 정(+)의 영향을 미쳤다. 정서적신뢰는 응원하는 팀의 경기패배 후 스포츠팬의 재관람의도에 정 $(+)$ 의 영향을 미쳤다. 인지적신뢰는 응원하는 팀의 경기패배 후 스포츠팬 의 전환의도에 부(-)의 영향을 미쳤다. 정서적신뢰는 응원하
는 팀의 경기패배 후 스포츠팬의 전환의도에 유의미한 영향 을 미치지 못했다. 팀 동일시의 조절효과는 정서적신뢰가 전 환의도에 미치는 영향에만 나타났다. 스포츠팬의 응원하는 팀에 대한 신뢰는 패배 이후 스포츠팬 행동에 영향을 미치는 것을 알 수 있다. 구체적으로 인지적신뢰와 정서적신뢰는 팀 이 패배를 했음에도 재관람의도에 정(+)적인 영향을 미쳤는 데 이는 패배로 인한 재관람의도 감소를 막아주는 것으로 해 석할 수 있다. 또한 인지적신뢰의 경우 전환의도를 감소시켜 주는 효과를 보였다. 연구결과로 미루어볼 때, 스포츠구단 및 마케터는 우선적으로 스포츠팬이 팀에 대한 인지적신뢰를 가 질 수 있는 노력을 해야 한다. 구체적으로, 승리에 대한 피드 백을 강화하고 선수보강 및 감독 전술 등 구단이 가진 경쟁력 과 강점을 팬에게 전달해야 한다. 또한 패배 시에는 패배원인 에 대한 피드백과 이를 보완할 수 있는 능력을 구단과 팀이 가지고 있다는 것을 끊임없이 팬에게 전달할 필요가 있다.

그동안 서비스실패가 신뢰에 영향을 미친다는 보고는 많 지만, 기존에 가지고 있는 신뢰가 고객행동에 영향을 미치는 과정에 대한 연구는 미진하였다. 이는 서비스실패 또는 패배 가 소비자 신뢰에 영향을 주는 단선적 결과에는 많은 관심이 있었지만, 소비자가 기존에 가지고 있던 신뢰가 실제 행동을 어떻게 완화하거나 증대시키는지에 대한 지식 생산에는 관 심이 부족했음을 시사한다. 이 연구는 소비자와 구단을 이어 주는 중요 요인인 신뢰연구 분야에서 그 동안 다루지 못한 부 분을 밝혀냈다는 점에서 그 의의가 있다. 또한 인지적신뢰와 정서적신뢰 두 유형에 따라 소비자 행동의도가 달라지는 것 을 확인하였다. 서로 다른 특성을 바탕으로 형성되는 두 신 뢰에 따라 소비자 행동이 달라지는 것을 확인하였다. 이는 현장의 마케팅 목적에 맞는 의사결정을 내리기 위해 꼭 필요 한 지식이다. 스포츠 마케팅에서는 소비자의 특성을 파악하 고 이에 맞는 경영전략을 수립하는 것이 매우 중요하다. 이 연구는 소비자 특성 중 기존에 가지고 있는 신뢰에 초점을 맞 추었다. 이는 스포츠 산업 종사자들 실무에서 활용할 수 있 는 지식이라고 할 수 있다. 또한 스포츠 경영학 연구에서 신 뢰는 단일한 요인으로 측정되고 사용되었다. 이 연구를 통해 신뢰를 조금 더 세분화된 개념으로 연구할 수 있는 기반이 될 것이라고 생각하며, 다른 변인들과 신뢰의 관계를 규명하기 위한 추가 연구들에 도움이 될 수 있을 것이다.

연구목적 달성을 위해 여러 선행연구를 바탕으로 변인 간 의 관계를 규명하려 노력했다. 그러나 이 연구에서 충분하게 해결하지 못한 한계가 존재해 후속연구를 위한 제언을 하고 
자 한다. 첫째, 이 연구는 스포츠팬에게 패배경험을 자극하 기 위해 신문 기사를 이용하였다. 기사를 이용하는 방법은 다양한 선행연구에서 사용된 방법이다. 하지만, 기사를 사용 하는 방법은 스포츠를 관람하는 동안 발생하는 다양한 감정 과 패배 순간에 발생하는 순간적 감정을 정확하게 자극하지 못했을 가능성이 존재한다. 본 연구에서는 그러한 한계점을 시간과 비용적 측면의 한계로 인해 극복하지 못하였다. 다음 연구에서는 패배 순간에 발생하는 세부적 감정을 확인하고 소비자 행동을 검증하는 것이 의미가 있을 것으로 사료된다. 둘째, 인지적신뢰와 스포츠팬 행동에 팀 동일시 수준에 따른 조절효과가 나타나지 않았다. 따라서 추후 연구에서는 스포 츠 팬의 인지적신뢰가 행동의도에 미치는 영향을 조절하는 요인들을 찾아낸다면 좋을 것이다. 구체적으로 소비자의 인 지적과정과 행동의도에 연결성이 높은 변인을 찾아내는 과 정이 필요하다. 셋째, 이 연구에서는 패배자극물의 효과 극 대화를 위해 상대적으로 미국 내에서 관심이 적은 축구 종목 을 대상으로 조사하였다. 하지만 이는 참여자의 종목 관여도 를 고려하지 못했다는 제한점으로 작용하였다. 또한 앞선 노 력에도 불구하고 여전히 참여자가 제시된 자극물이 거짓이 라고 느꼈을 가능성을 배제할 수 없다. 마지막으로 이 연구 는 패배 원인이나 게임과정을 세부적으로 분류하지 못했다. 선행연구들을 살펴보면 게임과정의 차이에 따른 소비자 행 동변화가 나타났다(Kim, Magnusen, \& Lee, 2017). 그러 나 이 연구에서는 게임결과나 과정에 대한 세부적 분류를 하 지 못했다. 다음 연구에서는 세부적인 게임 결과와 과정을 분류하고 이에 따라 소비자행동에 어떤 영향을 미치는지 살 펴본다면 의미 있는 연구가 될 것으로 생각한다.

\section{참고문헌}

Anderson, J. C., \& Gerbing, D. W. (1988). Structural equation modeling in practice: A review and recommended two-step approach. Psychological bulletin, 103(3), 411-423.

Ashforth, B. E., \& Mael, F. (1989). Social identity theory and the organization. Academy of management review, 14(1), 20-39.

Becerra, E. P., \& Korgaonkar, P. K. (2009). Hispanics' information search and patronage intentions online. Journal of Electronic Commerce Research, 10(2), 76-93.
Biscaia, R. (2015). Spectators' experiences at the sport and entertainment facility: The key for increasing attendance over the season. Sport \& Entertainment Review, 1(2), 57-64.

Biscaia, R., Correia, A., Rosado, A., Maroco, J., \& Ross, S. (2012). The effects of emotions on football spectators' satisfaction and behavioural intentions. European Sport Management Quarterly, 12(3), 227-242.

Branvold, S. E., Pan, D. W., \& Gabert, T. E. (1997). Effects of winning percentage and market size on attendance in minor league baseball. Sport Marketing Quarterly, 6(4), $35-42$.

Chai, J. C. Y., Malhotra, N. K., \& Alpert, F. (2015). A two-dimensional model of trust-value-loyalty in service relationships. Journal of Retailing and Consumer Services, 26, 23-31.

Choi, C. J. (2014). Structural Causal Relations Between Store Characteristics and Cognitive Trust and Affective Trust and Relationship Commitment and Loyalty in Retail Services Setting. Journal of Marketing Studies, 22(4), 155-174.

Choi, Y. J., \& Choi, H. (2017). Mediating Effect of Cognitive Trust and Emotional Trust on Satisfaction of Mobile Easy Payment Services According to Gender. Journal of the Korea Contents Association, 17(11), 525-532.

Cho, Y. M. (2017). The Effects of Perceived Organizational Support, Cognitive-Affective Trust on Life Insurance Agents Turnover Intention. Journal of CEO and Management Studies, 20(4), 175-190.

Cialdini, R. B., \& Richardson, K. D. (1980). Two indirect tactics of image management: Basking and blasting. Journal of personality and social psychology, 39(3), 406-415.

Creyer, E. H., \& Ross, W. T. (1999). The development and use of a regret experience measure to examine the effects of outcome feedback on regret and subsequent choice. Marketing Letters, 10(4), 373-386.

Cunningham, G. B., \& Kwon, H. (2003). The theory of planned behaviour and intentions to attend a sport event. Sport Management Review, 6(2), 127-145.

Doosje, B., Branscombe, N. R., Spears, R., \& Manstead, A. S. (1998). Guilty by association: When one's group has a negative history. Journal of personality and social psychology, 75(4), 872-886. 
Duhachek, A. (2005). Coping: A multidimensional, hierarchical framework of responses to stressful consumption episodes. Journal of Consumer research, 32(1), 41-53.

Dwyer, F. R., Schurr, P. H., \& Oh, S. (1987). Developing buyer-seller relationships. Journal of marketing, 51(2), 11-27.

Fisher, R. J., \& Wakefield, K. (1998). Factors leading to group identification: A field study of winners and losers. Psychology \& Marketing, 15(1), 23-40

Fitzsimons, G. J. (2000). Death to Dichotomizing, Journal of Consumer Research, 35(1), 5-8.

Fornell, C., \& Larcker, D. F. (1981). Evaluating structural equation models with unobservable variables and measurement error. Journal of marketing research, 18(1), $39-50$.

Funk, D. C., \& James, J. D. (2006). Consumer loyalty: The meaning of attachment in the development of sport team allegiance. Journal of Sport Management, 20(2), 189-217.

Garbarino, E., \& Johnson, M. S. (1999). The different roles of satisfaction, trust, and commitment in customer relationships. Journal of marketing, 63(2), 70-87.

George, D., \& Mallery, P. (2010). SPSS for Windows step by step. A simple study guide and reference (10. Bask1). GEN, Boston, MA: Pearson Education, Inc.

Ha, B. C., \& Nam, H. (2015). The Effect of Emotional Trust and Cognitive Trust on Mutual Information Sharing and Logistics Performance. Korean Journal of Logistics, 23(2), 67-87.

Ha, H. Y., John, J., John, J. D., \& Chung, Y. K. (2016). Temporal effects of information from social networks on online behavior: the role of cognitive and affective trust. Internet Research, 26(1), 213-235.

Ha, J. H. (2010). An examination of the relationships among team identification, attitude importance, resistance to change, and intention to attend future games to a collegiate basketball team. Korean Society For Sport Management, 15(2), 15-27.

Ha, T., \& Kim, Y. M. (2021). The Structural Relationship among Hedonic Value, Self Image Congruency, Club Trust, Club Emotion, Club Commitment and Reviewing Intention of WKBL Spectator. The Korean Journal of
Physical Education, 60(2), 49-65.

Han, D., Duhachek, A., \& Agrawal, N. (2016). Coping and construal level matching drives health message effectiveness via response efficacy or self-efficacy enhancement. Journal of Consumer Research, 43(3), 429-447.

Han, D., Mahony, D.F. and Greenwell, T.C. (2016), "A comparative analysis of cultural value orientations for understanding sport fan motivations", International Journal of Sports Marketing and Sponsorship, 17(3), 260-276.

Han, H., Kim, W., \& Hyun, S. S. (2011). Switching intention model development: Role of service performances, customer satisfaction, and switching barriers in the hotel industry. International Journal of Hospitality Management, 30(3), 619-629.

Han, J. W., Kwon, H. I., \& Noh, S. C. (2013). The Effect of CSR of a Professional Sports Team on Team Image: The Moderating Role of CSR Fit and Team Identification. The Korean Journal of Physical Education, 52(2), 313-326.

Harris, M. M., \& Schaubroeck, J. (1988). A meta analysis of self supervisor, self peer, and peer supervisor ratings. personnel psychology, 41(1), 43-62.

Hirt, E. R., Zillmann, D., Erickson, G. A., \& Kennedy, C. (1992). Costs and benefits of allegiance: Changes in fans' self-ascribed competencies after team victory versus defeat. Journal of personality and social psychology, 63(5), 724-738.

Hong, S. P. (2012). Examination of an Adaptive Model of Technology Acceptance Model and Trust for Online Purchasing Intentions of Sport Products'. The Korean Journal of Physical Education, 51(6), 201-213.

Hong, S., Malik, M. L., \& Lee, M. K. (2003). Testing configural, metric, scalar, and latent mean invariance across genders in sociotropy and autonomy using a non-Western sample. Educational and psychological measurement, 63(4), 636-654.

Inman, J. J., \& McAlister, L. (1994). Do coupon expiration dates affect consumer behavior?. Journal of Marketing Research, 31(3), 423-428.

Irwin, J. R., \& McClelland, G. H. (2003). Negative consequences of dichotomizing continuous predictor variables. Journal of Marketing Research, 40(3), 366-371. 
Jang, E. W., Ko, Y. J., Wann, D., \& Chang, Y. (2017). The relative effects of game outcome and process on fans' media consumption experiences. European Sport Management Quarterly, 17(5), 635-658.

Jeong, S. H. (2020). The Effect of Online Sporting Goods Consumer' Technology Acceptance Factors on Shopping Mall Trust, Satisfaction, and Future Consumption Behaviors. The Korean Journal of Physical Education, 59(4), 191-207.

Jo, Y. A. (2015). The Correlations among Trust, Satisfaction, Commitment, and Relation-Continuing Intention for Internet foundation Fashion Shopping Mall. Asia-Pacific Journal of Business Venturing and Entrepreneurship, 10(6), 155-165.

Johnson, D., \& Grayson, K. (2005). Cognitive and affective trust in service relationships. Journal of Business research, 58(4), 500-507.

Jones, M. V., Lane, A. M., Bray, S. R., Uphill, M., \& Catlin, J. (2005). Development and validation of the Sport Emotion Questionnaire. Journal of Sport and Exercise Psychology, 27(4), 407-431.

Keh, H. T., \& Xie, Y. (2009). Corporate reputation and customer behavioral intentions: The roles of trust, identification and commitment. Industrial marketing management, 38(7), 732-742.

Keaveney, S. M. (1995). Customer switching behavior in service industries: An exploratory study. Journal of marketing, 59(2), 71-82.

Kim, B. S., \& Kim, H. R. (2016). The Effect of Swimming pools Service Quality on Parental Trust, Adherence and Recommendation Intention. Journal of the Korean society for Wellness, 11(4), 205-221.

Kim, D., Han, J. W., \& Ko, I. (2019). The mediating effect of team image in the relationship between strategic CSR and spectator intention to professional baseball game attendance: Moderated mediation effect of team identification. The Korean Journal of Physical Education, 58(5), 107-119.

Kim, J. W., Magnusen, M., \& Lee, H. W. (2017). Existence of mixed emotions during consumption of a sporting event: A real-time measure approach. Journal of Sport Management, 31(4), 360-373.
Kim, K. C., Kim, Y. M., \& Hur, J. (2010). Structural Relationship among Motives of Web-usage, Website Image, Team Identification, Team Emotion and Viewing Intention for Professional Basketball Team. Korean Journal of Sports Science, 21(1), 1063-1075.

Kim. Y. M. (2005). The Effect of Spectatorship Satisfaction of Sports Event on Trustworthiness of Event, Commitment of Event and Re-spectatorship Intention. Korean Journal of Sport Science, 16(2), 106-118.

Kim, Y. M. (2010). The Effect of Spectating Value of Professional Baseball on Satisfaction with Spectating, Attitude toward a Team, Team Image, Team Identification, $\&$ Intention of Revisit. Korean Journal of Sports Science, 21(4), 1569-1581.

Kim, Y. M., Kim, A. R., \& Kim, K. H. (2012). Relationship Among Pro-football Spectators' Attitude Toward Spectating, Spectating Satisfaction, Team Trust, Team Identification, Sponsor Identification, Sponsor Image, Purchase Intention and Word-of-mouth. Korean Society For Sport Management 17(4), 13-30.

Kim, Y. M., Lee, K. S., \& Lee. J. C (2003). The Relationship between Game Attendance Factors, Team Image, Team Identification, and Spectatorship Intention. Korean Society For Sport Management 8(3), 1-14

Kim, Y. K., \& Trail, G. (2011). A conceptual framework for understanding relationships between sport consumers and sport organizations: A relationship quality approach. Journal of sport management, 25(1), 57-69.

Kline, R. B. (2015). Principles and practice of structural equation modeling. Guilford publications.

Klein, A., \& Moosbrugger, H. (2000). Maximum likelihood estimation of latent interaction effects with the LMS method. Psychometrika, 65(4), 457-474.

Kotler, P., Bowen, J. T., \& Makens, J. C. (2006). Marketingfor hospitality and tourism (4th ed.). NJ : Pearson Prentice Hall.

Kwon, H. (2011). Social Identity Theory, Organizational Identification, and Team Identification: Conceptual Review on the Links. Korean Society For Sport Management, 16(5), 67-77.

Kwon, H. (2019). Theoretical challenges of team identification. Korean Journal of Sport Science, 30(3), 529-539

Kwon, H., \& Choi, M. (2018). The relationship between team 
identification and consumption behaviors using a meta-analysis: Intention to attend sport events and to purchase sport team licensed merchandise. Korean Journal of Sport Science, 29(2), 315-327.

Lazarus, R. S., \& Folkman, S. (1984). Stress, appraisal, and coping. Springer publishing company.

Lewicki, R. J., \& Bunker, B. B. (1995). Trust in relationships. Administrative Science Quarterly, 5(1), 583-601.

Lewicki, R. J., \& Tomlinson, E. C. (2003). Trust and trust building. Beyond intractability, 305-315.

Lee, S. H., \& Hong, J. B. (2016). Relationships among Attributes of Social Commerce, Purchase Satisfaction, Trust and Repurchase Intention in Sports Product Purchase. The Korean Journal of Physical Education, 55(6), 349-360.

Lee, Y. G., \& Joo, H. C. (2020). The relationship among the 4Cs strategy of outdoor brand, brand attitude, brand trust, and future behavior intention. Korean Journal of Sport Management, 25(1), 43-57

Lim, K. H., \& Kim, K. H. (2019). Structural Relationship of Involvement in Marine Leisure Sports, Trust, Immersion and Purchase Behavior Korean Society For Sport Management, 58(2), 259-270.

Loewenstein, G. F., Weber, E. U., Hsee, C. K., \& Welch, N. (2001). Risk as feelings. Psychological bulletin, 127(2), 267-286.

Lock, D., \& Heere, B. (2017). Identity crisis: A theoretical analysis of 'team identification'research. European Sport Management Quarterly, 17(4), 413-435.

Madrigal, R. (1995). Cognitive and affective determinants of fan satisfaction with sporting event attendance. Journal of leisure research, 27(3), 205-227.

Madrigal, R. (2003). Investigating an evolving leisure experience: Antecedents and consequences of spectator affect during a live sporting event. Journal of leisure research, 35(1), 23-48.

Madrigal, R. (2008). Hot vs. cold cognitions and consumers' reactions to sporting event outcomes. Journal of Consumer Psychology, 18(4), 304-319.

Madrigal, R., \& Chen, J. (2008). Moderating and mediating effects of team identification in regard to causal attributions and summary judgments following a game outcome. Journal of Sport Management, 22(6), 717-733.

Mael, F., \& Ashforth, B. E. (1992). Alumni and their alma mater: A partial test of the reformulated model of organizational identification. Journal of organizational Behavior, 13(2), 103-123.

Magnusen, M., Kim, J. W., \& Kim, Y. K. (2012). A relationship marketing catalyst: The salience of reciprocity to sport organization - sport consumer relationships. European Sport Management Quarterly, 12(5), 501-524.

McAllister, D. J. (1995). Affect-and cognition-based trust as foundations for interpersonal cooperation in organizations. Academy of management journal, 38(1), 24-59.

Meredith, W. (1993). Measurement invariance, factor analysis and factorial invariance. Psychometrika, 58(4), 525-543.

Moon, S. H., \& Kim, J. H. (2016). The Effect of Corporate Social Responsibilities and Creating Shared Value on Cognitive/Emotional Trust and Loyalty: Focused on the Discount Stores. Journal of Distribution and Management Research, 19(3), 97-109.

Nisbett, R. E., Caputo, C., Legant, P., \& Marecek, J. (1973). Behavior as seen by the actor and as seen by the observer. Journal of personality and Social Psychology, 27(2), 154-164.

Noh, S. C., Han, J. W., \& Kwon, H. I. (2013). The Effect of CSR of a Professional Sports Team on Team Image: The Moderating Role of CSR Fit and Team Identification. The Korean Journal of Physical Education, 52(2), 313-326.

Nunnally, J. C., \& Bernstein, I. H. (1994). Psychometric Theory (McGraw-Hill Series in Psychology) (Vol. 3). New York: McGraw-Hill.

Oliver, R. L. (1993). Cognitive, affective, and attribute bases of the satisfaction response. Journal of consumer research, 20(3), 418-430.

Ozdemir, S., Zhang, S., Gupta, S., \& Bebek, G. (2020). The effects of trust and peer influence on corporate brand-consumer relationships and consumer loyalty. Journal of Business Research, 117, 791-805.

Park, B. S., Won, D. Y., \& Cho, K. M. (2013). A Structural Relationships between Constraints of Korea Professional Baseball Spectators and Re-Attend Intention: Moderating Effect of Team Identification. The Korean Journal of Physical Education, 52(5), 481-497.

Park, H. W., \& Hong, S. P. (2020). Effects of Sports 
Influencer's Use Motivations on Trust and Consumer Behaviors. The Korean Journal of Physical Education, 59(6), 263-273.

Park, M. R., Lee, S. H., Hong, S. H., \& Lee, M. J. (2009). The Effects of Cognitive and Affective Trust on Department Store Shopping. Journal of Marketing Studies, 4(44), 1-34.

Park, S. H. (2003). Spectators' differences in involvement, loyalty, intention to repurchasing, and intention to recommendation according to socio-demographic characteristics at Professional Baseball Games. Korean Society For Sport Management, 8(2), 375-393.

Partridge, J. A., Wann, D. L., Zapalac, R., Grieve, R., \& Lanter, J. (2020). Vicarious Shame in Sport Fans. Journal of Sport Behavior, 42(1), 103-119.

Pavlou, P. A., \& Chellappa, R. K. (2001). The role of perceived privacy and perceived security in the development of trust in electronic commerce transactions. Information System Research, 11(1), 18-36.

Portes, A. (1998). Social capital: Its origins and applications in modern sociology. Annual review of sociology, 24(1), 1-24.

Podsakoff, N. P. (2003). Common method biases in behavioral research: a critical review of the literature and recommended remedies. Journal of Applied Psychology, 88(5) 879-903.

Punyatoya, P. (2019). "Effects of cognitive and affective trust on online customer behavior", Marketing Intelligence \& Planning, 37(1), 80-96.

Qureshi, I., Fang, Y., Ramsey, E., McCole, P., Ibbotson, P., \& Compeau, D. (2009). Understanding online customer repurchasing intention and the mediating role of trust - an empirical investigation in two developed countries. European Journal of Information Systems, 18(3), 205-222.

Schurr, K. T., Wittig, A. F., Ruble, V. E., \& Ellen, A. S. (1988). Demographic and personality characteristics associated with persistent, occasional, and non-attendance of university male basketball games by college students. Journal of Sport Behavior, 11(1), 3-17.

Sengupta, A. S., Balaji, M. S., \& Krishnan, B. C. (2015). How customers cope with service failure? A study of brand reputation and customer satisfaction. Journal of Business Research, 68(3), 665-674.

Seo, H., \& Kwon, Y. (2020). The Relationships among Team
Identification, Stress-Coping Behaviors to the COVID-19 Outbreak, and Intention to Revisit of Professional Sports Fans. Korean Journal of Sport Management, 25(4), 47-62.

Seok, B. G., Cho, J. H., \& Ko, K. J. (2017). Analysis of Relationship among the Quality of Human and Material Service and Consumer Trust in order to Increase Persistent Usage of University Fitness Center. The Korean Journal of Physical Education, 56(5), 497-509.

Snyder, C. R., Higgins, R. L., \& Stucky, R. J. (1983). Excuses: Masquerades in search of grace (No. 341). John Wiley \& Sons.

Sweeney, J., \& Swait, J. (2008). The effects of brand credibility on customer loyalty. Journal of retailing and consumer services, 15(3), 179-193.

Tabachnick, B. G., Fidell, L. S., \& Ullman, J. B. (2007). Using multivariate statistics (Vol. 5, pp. 481-498). Boston, MA: Pearson.

Tajfel, H., Billig, M. G., Bundy, R. P., \& Flament, C. (1971). Social categorization and intergroup behaviour. European journal of social psychology, 1(2), 149-178.

Trope, Y., \& Liberman, N. (2003). Temporal construal. Psychological review, 110(3), 403-421.

Trail, G. T., \& James, J. D. (2001). The motivation scale for sport consumption: Assessment of the scale's psychometric properties. Journal of sport behavior, 24(1), 108-127.

Trail, G. T., Fink, J. S., \& Anderson, D. F. (2003). Sport spectator consumption behavior. Sport Marketing Quarterly, 12(1), 8-17.

Van Leeuwen, L., Quick, S., \& Daniel, K. (2002). The sport spectator satisfaction model: A conceptual framework for understanding the satisfaction of spectators. Sport Management Review, 5(2), 99-128.

Walton, A., \& Hume, M. (2012). Examining public hospital service failure: the influence of service failure type, service expectations, and attribution on consumer response. Journal of Nonprofit \& Public Sector Marketing, 24(3), 202-221.

Wakefield, K. L., \& Sloan, H. J. (1995). The effects of team loyalty and selected stadium factors on spectator attendance. Journal of sport management, 9(2), 153-172.

Wann, D. L., \& Branscombe, N. R. (1990). Die-hard and fair-weather fans: Effects of identification on BIRGing and 
CORFing tendencies. Journal of Sport and Social issues, 14(2), 103-117.

Wann, D. L., \& Branscombe, N. R. (1993). Sports fans: Measuring degree of identification with their team. International Journal of Sport Psychology, 24(1), 1 - 17.

Wann, D. L., \& Schrader, M. P. (1997). Team identification and the enjoyment of watching a sporting event. Perceptual and Motor Skills, 84(3), 954-954.

Wesbrook, R. A., \& Oliver, R. L. (1991). The dimensionality of consumption emotion pattern and customer satisfaction. Journal of consumer research, 18(1), 84-91.

Ye, C., Hofacker, C. F., Peloza, J., \& Allen, A. (2020). How online trust evolves over time: The role of social perception. Psychology \& Marketing, 37(11), 1539-1553.

Yim, B. H., \& Byon, K. K. (2018). The Influence of Emotions on Game and Service Satisfaction and Behavioral Intention in Winning and Losing Situations: Moderating Effect of Indentification with the Team. Sport Marketing Quarterly, 27(2). 93-106

Yoon, S. J., Han, J. W., \& Yoo, J. S. (2013). The impact of professional baseball team brand association on team loyalty Moderating role of team identification. Korean Journal of Sports Science, 22(1), 515-529

Yoshida, M., \& James, J. D. (2010). Customer satisfaction with game and service experiences: Antecedents and consequences. Journal of sport management, 24(3), 338-361.

Yu, J. S., Lee, A. J., \& Han, H. S. (2016). Investigating The Relationships Among Service Failure, Dissatisfaction, Trust, Negative Word-of-Mouth, and Switching Intention in The Restaurant Industry. Korean Journal of Hospitality \& Tourism, 25(7), 51-69.

Zeelenberg, M., \& Pieters, R. (2004). Beyond valence in customer dissatisfaction: A review and new findings on behavioral responses to regret and disappointment in failed services. Journal of business Research, 57(4), 445-455.

Zeithaml, V. A., Berry, L. L., \& Parasuraman, A. (1996). The behavioral consequences of service quality. Journal of Marketing, 60(2), 31-46.

Zur, A., Leckie, C., \& Webster, C. M. (2012). Cognitive and affective trust between Australian exporters and their overseas buyers. Australasian Marketing Journal, 20(1), 73-79. 


\title{
인지적신뢰와 정서적신뢰가 팀 패배 후 스포츠팬 행동에 미치는 영향: 미국 국가대표 남자 축구 경기 시청자를 중심으로
}

\author{
장남경 ${ }^{1}$, 장지석 ${ }^{1}$, 김유겸 ${ }^{2}$ \\ ${ }^{1}$ 서울대학교 박사과정(수료) \\ ${ }^{2}$ 서울대학교 교수
}

[목적] 본 연구는 팀 패배 후 스포츠 팬의 팀에 대한 신뢰가 향후 행동의도에 어떤 영향을 미치는지 확인하 는데 그 목적이 있다. [방법] 아마존 Mechanical turk를 활용하여 총 288명의 미국인의 인지적신뢰, 정서적 신뢰, 팀 동일시, 재관람의도, 전환의도를 측정하였다. SPSS 21.0과 Mplus 8을 활용하여 빈도분석, 신뢰도 분석, 확인적요인분석, 경로분석, 다집단 분석을 통해 가설을 검증하였다. [결과] 인지적신뢰는 응원하는 팀의 경기패배 후 스포츠팬의 재관람의도에 정(+)의 영향을 미쳤다. 정서적신뢰는 응원하는 팀의 경기패배 후 스포 츠팬의 재관람의도에 정(+)의 영향을 미쳤다. 인지적신뢰는 응원하는 팀의 경기패배 후 스포츠팬의 전환의도 에 부(-)의 영향을 미쳤다. 정서적신뢰는 응원하는 팀의 경기패배 후 스포츠팬의 전환의도에 유의미한 영향을 미치지 못했다. 팀 동일시의 조절효과는 정서적신뢰가 전환의도에 미치는 영향에만 나타났다. [결론] 본 연구 의 결과는 스포츠 팬이 기존에 가지고 있던 신뢰가 팀 패배 후에도 영향을 미친다는 점을 시사한다. 따라서 프로스포츠 구단은 스포츠팬에게 자신들의 능력에 대한 인지적신뢰와 팬과 팀의 연결성에 대한 믿음인 정서적 신뢰를 함께 확보해 나아갈 필요가 있다.

주요어: 인지적신뢰, 정서적신뢰, 재관람의도, 전환의도, 팀 동일시 